\title{
Reconstruction with Modular Endoprosthesis in Elbow Joint due to Oncological and Non-Oncologic Causes
}

\section{Dirsek Ekleminde Onkolojik ve Onkolojik Dışı Nedenlere Bağlı Yapılan Modüler Endoprotez İle Rekonstrüksiyon Uygulamalarımız}

\author{
Güray Toğral, Bedii Şafak Güngör
}

Dr. Abdurrahman Yurtaslan Onkoloji Eğitim Ve Araştırma Hastanesi Ortopedi Bölümü

Dergiye Ulaşma Tarihi: 04.04.2017 Dergiye Kabul Tarihi: 19.04.2017 Doi: 10.5505/aot.2017.87049

\section{ÖZET}

Giriş ve Amaç: Dirsek eklemi; primer ve metastatik kemik tümörleri için nadir bir tutulum bölgesidir. Bu bölgeyi ilgilendiren tümörlerin cerrahisi tedavisinde bölgedeki damar sinir yapıları nedeniyle ameliyat öncesi ve sonrası planlama çok dikkatli yapılmalıdır. Dirsek eklemi ve distal humerusu ilgilendiren tümör ve tümör dışı nedenlerle rezeksiyon ve sonrasında modüler endoprotez ile rekonstrükte edilen hastaların tedavisinin sonuçlarının değerlendirilmesi amaçladık.

Yöntem ve Gereçler: 2005-2016 yılları arasında kliniğimizde; dirsek eklemine onkolojik ve non-onkolojik nedenlerle rezeksiyon yapılıp modüler megaprotez ile rekonstrüksiyon yapılan 12 hastayı retrospektif olarak demografik, tümör protezi yapılma etiyolojisi, tümör özellikleri ve fonksiyonel alçıdan inceledik.

Bulgular: Çalışmaya 12 olgu dahil edildi, ortalama yaş 53(18-75)'tü. Hastaların 7'si erkekti. Ortalama takip süresi 33 ay(4-120 ay) di. Hastalardan 10 tanesine kemik tümör rezeksiyonu (7 hastada metastatik, 3 hastada primer) sonrası dirsek rekonstrüksiyonu yapılırken 2 hastaya daha önce geçirilmiş başarısız dirsek protezi nedeniyle uygulanmıştı. Ortalama Musculoskeletal Tumor Society (MSTS) skor 77(67-93) iken ortalama Mayo Elbow Performance Score (MEPS) skor 63 (45-80) olarak hesaplanmıştı. Hastaların operasyon öncesi görsel analog skala (VAS) skoru ortalama 7(6-9) iken operasyon sonrası bu değerler 5(4-6) olarak ölçülmüştü. 4 olguda komplikasyon (birer hastada geçici radial palsi, yüzeyel yara yeri enfeksiyonu, 2 hastada ise ulnar komponentde periprostatik kırık) gözlenmişti. Metastaza bağlı endoprotez yapılmış 6 hasta malesef ortalama 23 ay (9-35 ay) içinde kaybedilmiştir, kalan 6 hasta takip altındadır. Yumuşak doku fibrosarkomu tanılı hastada operasyon bölgesinde damar sinir pakesini tutan yumuşak doku nüksü nedeniyle rezeksiyon protezinden 14 ay sonra yüksek dirsek üstü amputasyon yapılmıştı.

Tartışma ve Sonuç: Dirsek eklemine modüler megaprotez uygulanan hastalarda yüksek oranda ağrısız bir dirsek, ön kol ve el bileği eklemi elde edilmekte, hasta ameliyattan sonra kısa süre içinde ilgili ekstremitesini kullanmaya başlamaktadır. Dahası yeterli cerrahi sınır elde edilmesini sağlayan agresif bir rezeksiyon; bu bölgeyi tutan primer lokal agresif tümörlerde potansiyel bir kür sağlayabilmektedir, ancak metastatik tümörlerde yeterli bir fonksiyonel sonuç sağlamasına karşın total yaşam beklentisine çok katkı sağlamamaktadır. Anahtar Kelimeler: Dirsek Eklemi, Modüler Endoprotez, Rekonstrüksiyon

\footnotetext{
ABSTRACT

Introduction: Elbow joint is a rare site of involvement for primary and metastatic bone tumors. Surgery involving this area should be done carefully because of the vascular structures and nerve related with the region. We aimed to evaluate the outcome of patients who were reconstructed with a modular endoprosthesis involving the elbow joint and dis tal humerus due to tumor resection and other causes.

Material and Methods: We retrospectively reviewed the demographics, tumor prothesis etiology, tumor characteristics and functional plaster of 12 patients who underwent resection with oncologic and non-oncological reasons for the elbow joint and reconstruction with modular megapros the sis between 2005-2016 in our clinic.

Results : Twelve cases were included in the study, with a mean age of 53 (18-75) years. Seven of the patients were male. The mean follow-up period was 33 months (4-120 months). Elbow reconstruction was performed due to bone tumor resection in 10 patients ( 7 patients metastatic, 3 patients primer) while following pre vious unsuccessful elbow prosthesis in 2 patients. The mean Musculoskeletal Tumor Society (MSTS) score was 77 (67-93) while the mean Mayo Elbow Performance Score (MEPS) score was 63 (45-80). The preoperative visual analog scale (VAS) score of the patients was 7 (6-9), whereas these values were reduced to 5 (4-6) postoperatively. Complications were observed in 4 cases: transient radial palsy in 1, superficial wound infection in 1 and periprostatic fracture in ulnar component in 2 patients.
} 
Dis cussion and Conclusion: In patients who have applied modular megaprosthes is to the elbow joint, a painless elbow, forearm and wrist joint are obtained at a high rate and the patient begins to use the extremity shortly after the operation. Furthermore, an aggressive resection ensuring that adequate surgical margin is achieved; provides a potentialcure for primary local aggressive tumors, although for metastatic tumors it provides satisfactory functional result but do not contribute much to the total life expectancy.

Ke ywords : Elbow, Modular Endopros the sis, Reconstruction

\section{Giriş}

Dirsek eklemi primer ve metastatik kemik tümörlerinin yerleşimi için yaygın bir bölge değildir (1). Yerleşim sıklığı olarak bütün kemik tümörlerinin \% lini oluşturmaktadır $(2,3)$. Primer ve metastatik kemik tümörlerine bağl1 üst ekstremite tutulumu olan hastaların cerrahi tedavisinde rekonstrüktif cerrahi 1970 lerden sonra başlamıştır. Tümör dışı nedenlerle modüler dirsek eklem protezleri yaşlı hastaların komplike kırıklarında, şiddetli osteoartrit ve romatoid artirite bağlı dirsek eklemi dejenerasyonlarında da yapılabilmektedir(4). Günümüzde üst ekstremite tümörlerinin tedavisin de koruyucu cerrahideki amaç tümörün lokal kontrolünü sağlamak ve maksimum fonksiyonel bir dirsek eklemi elde ederek hastayı amputasyondan kurtarmaktır. Dirsek çevresini tutan metastatik tümörlerin palyatif tedavisinde radyoterapi ve kemoterapi gibi seçenekler olmasına rağmen büyük çaplı kemik yokluğuna neden olan lezyonlar zamanla ekstremitede şiddetli ağrı ve fonksiyon kaybına yol açmaktadır. Tümör rezeksiyonu sonras1 oluşan kemik defektleri prostetik materyal veya segmental allogreftler kullanılarak rekonstrükte edilebilmektedir. Fakat allogreft kullanımı insitabilite, enfeksiyon, nonunion gibi multipl komplikasyonlara yol açarken başarısız bir eklem artroplastisi ise kötü fonksiyonel sonuçlara yol açabilmektedir. Üst ekstremite tümör rezeksiyonu distal humerus veya proksimal ulna nin eklem kısmının rezeksiyonunu çoğunlukla gerektirmekte bu bölgede bulunan hayati damar sinir yapıların zarar görmesi ise el bileği , dirsek eklemi ve elde ciddi fonksiyon kayılarına neden olabilmektedir. Dirsekte modüler protez uygulamaları nedeniyle çok yayın olmaması nedeniyle bu çalışmadaki amacımız dirsek eklemini tutan tümör ve tümör dışı nedenlerle yapılan rezeksiyon protezlerin klinik ve fonksiyonel sonuçları hakkında klinik tecrübelerimizi aktarmaktır. Klinik uygulamalarda çoğunlukla damar- sinir yapılarına daha kolay ulaşılacağı düşünülerek anterior yaklaşım kullanılmaktadır. Biz kliniğimiz de daha sonrasında gerekli olduğu vakalarda total humerus protezi yapılması için de uygun ve kullanımı da kolay olan uzatılmış lateral yaklaşımı tercih etmekteyiz.

\section{Yöntem ve Gereçler}

2005-2016 y1ları arasinda kliniğimizde; dirsek eklemine onkolojik ve nononkolojik nedenlerle rezeksiyon yapılıp modüler endoprotez ile rekonstrüksiyon yapılan 12 hastay1 retrospektif olarak demografik, tümör protezi yapılma etiyolojisi, tümör özellikleri ve fonksiyonel eklem değerleri açısından inceledik. Bütün hastalarda distal humerusta büyük çapta kemik kaybı olması nedeniyle klasik dirsek protezi yapma imkanı yoktu. Çalışmaya 12 olgu dahil edildi. Ortalama yaş 53(18-75)'tü. Hastaların 7'si erkek, 5 i bayandı. Ortalama takip süresi 33 ay(4-120 ay) d1. Hastalardan 10 tanesine kemik tümör rezeksiyonu ( 7 hastada metastatik, 3 hastada primer) sonras1 dirsek protezi ile rekonstrüksiyon yap1lırken 2 hastaya daha önce geçirilmiş başarısız dirsek protezi nedeniyle uygulanmıştı(Resim1). Hastaların evrelendirilmesi ve tümör yayılımının değerlendirilmesi direk grafi, BT(Bilgisayarlı Tomografi), MRG(Manyetik rezonans görüntüleme) ve sintigrafi ile yapıldı. PET( Pozitron Emisyon Taraması) ancak 2012 den sonraki takibe aldığımı hastalarda uygulanabildi. Hastaların tamamına açık biyopsi yapıld1.

3 hastanın kliniğimize başvuru nedeni patolojik kırıktı(Resim 2). Primer tümör olarak 1 hasta dirsek eklemi medyalinde yumuşak doku fibrosarkomunun kemik invazyonu, 1 hasta ewing sarkomu ve yine bir hasta kemiğin lokal invaziv dev hücreli tümörü nedeniyle opere edilmişti(Resim 3,4). Kemik metastazı olan hastalardan 3 tanesinde meme ca metastazı 1 er hastada sirasiyla renal hücreli karsinom(RCC), adenokarsinom, akciğer karsinomu, karsinom metastazı mevcuttu. Tümörler dirsek eklemine çok yakın olması nedeniyle eklem koruyucu küretaj ve sementleme gibi tedavileri yapma imkanı 
yoktu. Operasyonlar klasik anterior yaklaşım yerine uzun anterolateral yaklaşım ile gerçekleştirilmişti. Olgularda TIPSAN (TIPSAN T1bbi Aletler İzmir /TÜRKIYE) marka modüler dirsek eklemi protezi kullandık.

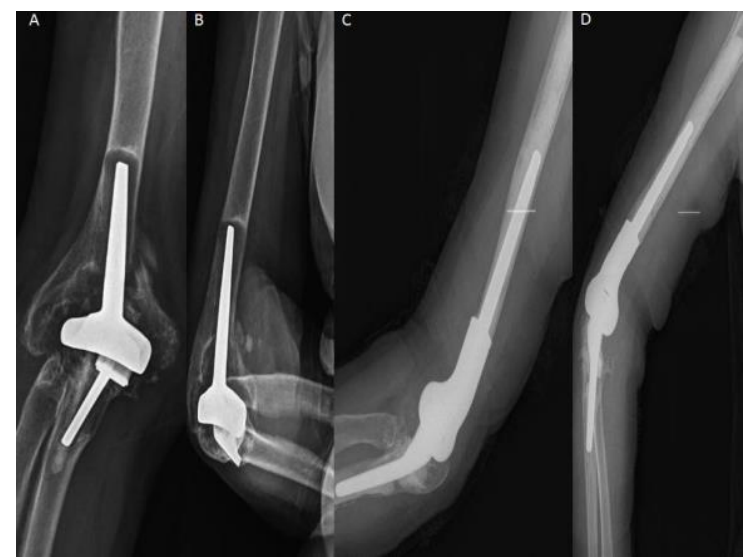

Resim 1. A.Preop AP grafi B.Preop lateral grafi C. Post op AP grafi D. Post op Lateral grafi

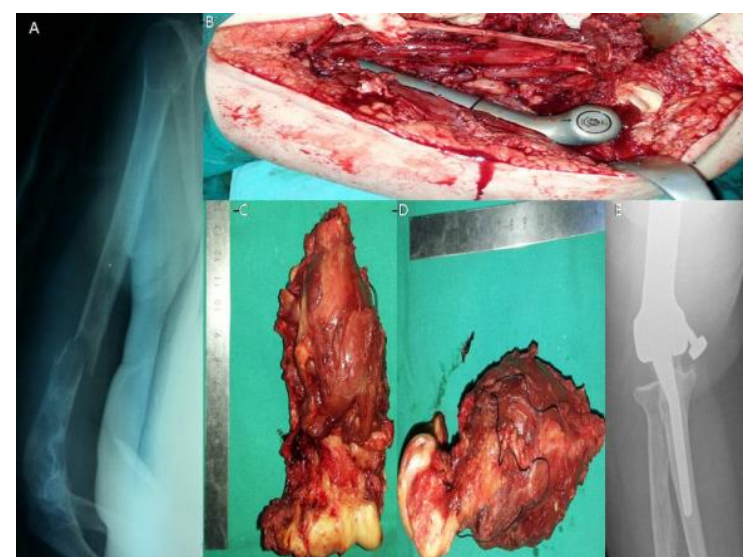

Resim 2. A.Metastaza bağlı patolojik kırık AP grafi B. Ameliyat görüntüsü C,D. operasyon Materyali D. Post op AP grafi menteşe vidasında gevşeme mevcut.

\section{Cerrahi Teknik}

Hasta; ilgili ekstremite 30 derece abdüksiyon da supin pozisyonda yatırılarak steril bir şekilde örtülür. Skapulanın altına 1 adet yükseltici konulması operasyon sirasinda kolaylık sağlayacaktır. Enfeksiyon açısından cerrahi drep kullanılması uygun olacaktır. Kliniğimizde proksimalde; deltopektorale doğru uzanan lateralde ulna kemiği boyunca devam eden uzatılmış longitüdinal lateral cerrahi yaklaşımı tercih etmekteyiz.

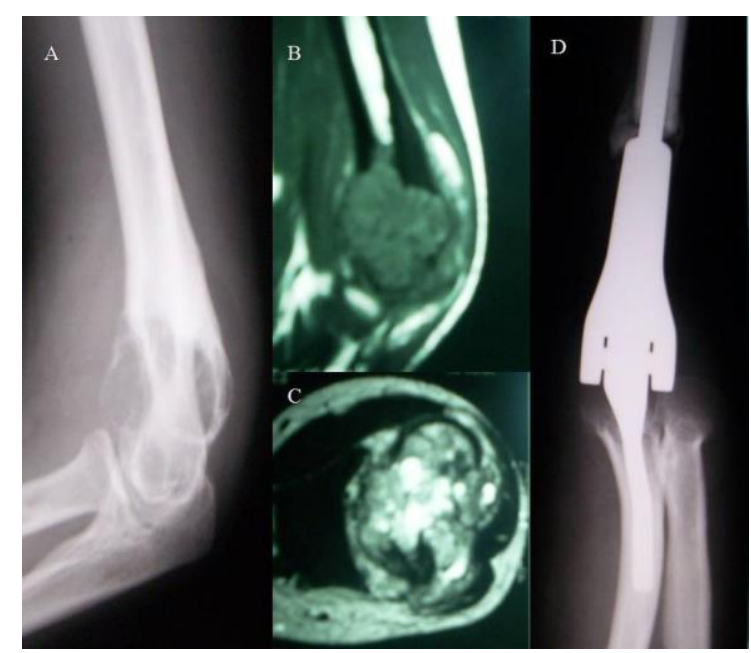

Resim 3. Dev Hücreli Tümörlü Hastanın A. Preop Lateral Grafi B. MR koronal görüntü C.MR aksiyel görüntü D.Post op AP grafi

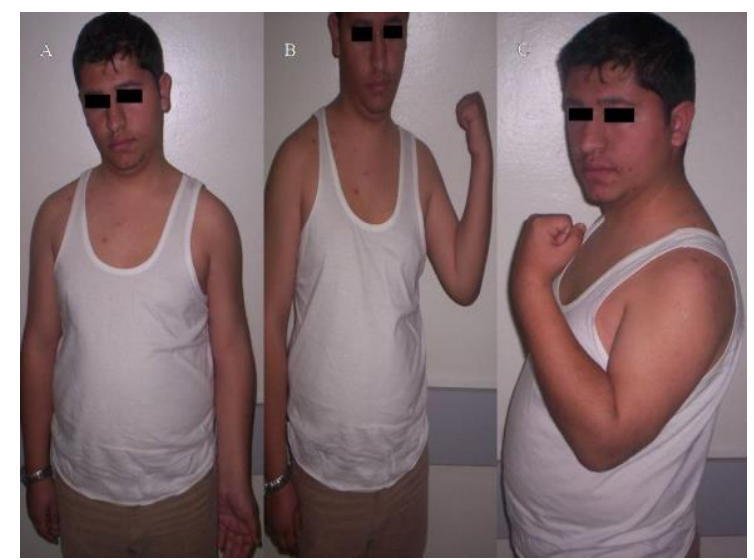

Resim 4. Dev hücreli tümör nedeniyle opere edilen hastanın A,B,C Post op dirsek eklemi hareketleri

İnsizyon sonras1 katlar anatomik planda geçilerek radial sinir; brakial ve brakiradyal kaslar arasından bulunarak serbestleştirilir. Proksimalde biceps ve triceps kasları arasındaki aralıktan girilerek nörovasküler yapılar ortaya çıkartılır. Median, ulnar ve medyal antebrakial sinirler izole edilerek askıya alınır. Brakial arter ve ven dikkatli bir şekilde tümörün yumuşak dokusundaki pseudokapsülden diseke edilir. Bu sırada median sinirin zarar görmemesine özen gösterilmelidir. Biseps kası korunmaya çalışılmalıdır. Genellikle burada tümör tutulumu olmaz. Tutulum olduğu durumlarda biseps çıkarılmalıdır. Buda kişide fleksiyon kaybında yol açacaktır. Pronotor teres ve ortak fleksör kaslar mediale deviye edilmelidir. Eğer lateral k1sımda brakiradialis ve ortak estensör gurupta rezeksiyon olacaksa posterior intraosseöz sinirin el bileği ekstansiyonunun sürdürülmesi için korunmalıdır. Triceps kası distal humerustan serbestleştirilir ve genellikle 
tümör yayılımına bağlı olarak medyal başı komple veya parsiyel eksize edilir. Lateral ve uzun baş1 genellikle korunur. Triceps tendonun olekranona yapışma yeri korunmalıdır. Osteotomize edilmemelidir. Sonrasinda humerus tümörün intramedüller uzanımından 2 $-3 \mathrm{~cm}$ üzerinden osteotomize edilmelidir. Devamında eklem kapsülü açılarak humeroulnar ve radiohumeral eklemler dezartiküle edilir. Oluşan boşluğun tedavisinde modüler segmental distal humerus rezeksiyon protezi kullanılır. Proksimal humerus intarmedüller olarak oyulur. Devamında uygun büyüklükteki stem çimentolu olarak yerleştirilir. Ulnar komponentte aynı seansta olekranon ve proksimal ulnaya çimentolu olarak yerleştirilir. Ulnar kemikte stemin girmesi için yer hazırlanırken burr kullanılabilir. Stem yerleştirildikten sonra skopi kontrolü yapılması uygun olacaktır. Çünkü sitemin yerleşimi sırasında ulnada periprostatik kırık olabilmektedir. Yumuşak dokunun iyi kapanabilmesi için uzun bir stem konulmamasına dikkat edilmelidir. Devamında distal humerus ve proksimal ulnay1 birbirine bağlayacak menteşe protez takılır. Eklem hareketleri kontrol edilir. İyi bir kanama kontrolü mutlaka yapılmalıdır. Brakioradialis ve ekstensör carpi radialis kasları kalan biceps ve triceps kaslarına stüre edilir ve dirsek eklem protezi üzeri örtülür. $\mathrm{Bu}$ işlemler yapılırken dirsek 60 derece fleksiyonda ve tam supinasyon da olmalıdır. Dren konmasını takiben katlar anatomik planda kapatılır. Postoperatif dönemde ödem kontrolü son derece önemlidir. Dirsek eklemi 60 derece fleksiyonda olacak şeklide atelde kalmalıdır. Dirsek eklem hareketleri yeterli yumuşak doku iyileşmesinin sağlanacağı 6 . haftaya kadar engellenmelidir. Pasif ROM hareketlerine operasyondan hemen sonra başlanabilir. 6. hafta sonunda dirsek eklemine 30-130 derece fleksiyona izin verecek şekilde hareket verilebilir. 12. haftada ise tam hareket başlanabilir.

\section{Bulgular}

Hastalardan 9 tanesinde sağ, 3 tanesinde sol dirsek eklemi tulumu mevcuttu. Ortalama rezeke edilen tümör boyutu $9.7 \mathrm{~cm}(5.5-14.5 \mathrm{~cm})$ idi. Ortalama Musculoskeletal Tumor Society (MSTS)(5) skor 77(67-93)(Resim 5) iken ortalama Mayo Elbow Performance Score

(MEPS)(6) skor 63 (45-80) olarak

hesaplanmıştı. Ewing sarkomlu hasta dışında omuz abduksiyon derecemiz 45 derecenin üzerinde idi. Hastaların operasyon öncesi görsel analog skala (VAS) skoru ortalama 7(69) iken operasyon sonrası bu değerler 5(4-6) olarak ölçülmüştü (7). 4 olguda komplikasyon (birer hastada geçici radial sinir palsi, yüzeyel yara yeri enfeksiyonu, 2 hastada ise ulnar komponentde periprostatik kırık) gözlenmişti. Radial sinir palsi gelişen hasta konservatif tedavi ile takip edildi. Ameliyat sonrası 6 . ayda sekelsiz olarak iyileşti. Yara yeri enfeksiyonu gelişen 1 hasta ise pansuman ve antibiyotik tedavisi devam ederken kontrollerde protezin menteşe eklemindeki vidada çıkma olması nedeniyle revizyon yapilmak zorunda kald1(Resim 3). Operasyon sirasinda ulnar komponentte periprostatik kırık olan iki vakadan operasyon sirasinda fark edilen olgu; serklaj tel ile onarılırken ameliyat sonrası görülen olgu ise atelde takip edilerek ve eklem hareketlerine geç başlanarak takip edildi. Ameliyat sonras1 6 haftada yeterli kaynama olduğu görüldü. Metastaza bağl1 endoprotez yapılmış hastalardan 6 tanesi ortalama 23 ay (935 ay) içinde kaybedilmiştir. Kalan 6 hasta sağ ve takip altındadır. En uzun takipli hastamız 120 ay ile kemiğin dev hücreli tümörü nedeniyle ameliyat ettiğimiz hastamızdır. $\mathrm{Bu}$ hastamızda kür sağlanmıştır. Ewing sarkom tanılı hastamızın takibin de ise humerus proksimalin de skip metastaz saptanması üzerine, total humerus protezine geçilmiştir. Yumuşak doku fibrosarkomu tanılı hastada ise operasyon bölgesinde damar sinir yumağını tutan yumuşak doku nüksü olması nedeniyle rezeksiyon protezinden 14 ay sonra yüksek dirsek üstü amputasyon yapılmak zorunda kalınmıştır(Resim 6). 


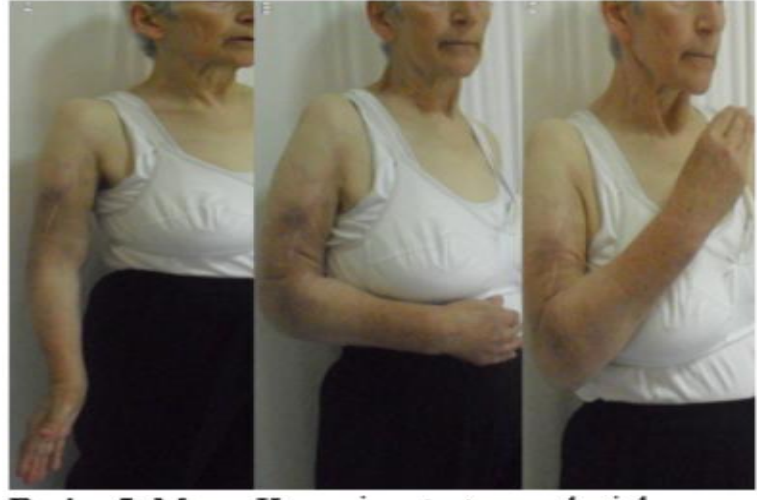

Resim 5. Meme Kanseri metastazi nedeniyle opere edilen hastanin $\mathrm{A}, \mathrm{B}, \mathrm{C}$ post op dirsek eklemi hareketleri

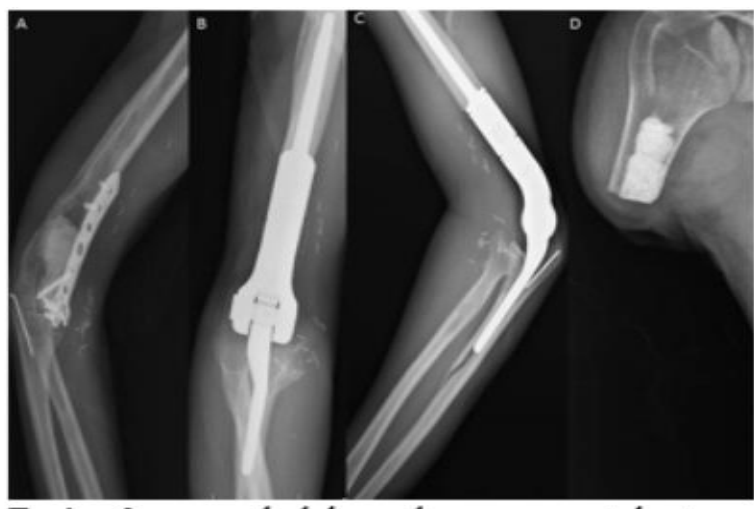

Resim 6. yumuşak doku sarkomu mevcut hastanın A. Preop lateral grafi B. Post op AP grafi C. Post op Lateral grafi D. Nüks nedeniyle ampute edilen hastanin post op grafisi.

Tablo 1: Hastaların Demografik Dağılımı

\begin{tabular}{|c|c|c|c|c|c|c|c|c|c|c|}
\hline HASTA & TANI & YASS & CINSIYYT & DURUM & $\begin{array}{l}\text { BAŞVURU } \\
\text { ŞIKAYET }\end{array}$ & KOMPLİKASYON & $\begin{array}{l}\text { MSTS } \\
\text { SKOR } \\
(\%)\end{array}$ & $\begin{array}{l}\text { MEPS } \\
\text { SKOR } \\
(\%)\end{array}$ & $\begin{array}{l}\text { VAS S } \\
\text { ÖNCE }\end{array}$ & KOR \\
\hline 1 & $\begin{array}{l}\text { Metastaz } \\
\text { (Meme) }\end{array}$ & 39 & K & $\begin{array}{l}\operatorname{Ex}(17 \\
\mathrm{AY})\end{array}$ & Kitle & Yok & 93 & 70 & 8 & 5 \\
\hline 2 & $\begin{array}{l}\text { Metastaz } \\
\text { (Meme) }\end{array}$ & 65 & K & $\begin{array}{l}\text { Ex(34 } \\
\text { ay) }\end{array}$ & $\begin{array}{l}\text { Patolojik } \\
\text { kırık }\end{array}$ & $\begin{array}{ll}\text { Radial } & \text { sinir } \\
\text { zedelenmesi } & \\
\end{array}$ & 67 & 65 & 7 & 5 \\
\hline 3 & $\begin{array}{l}\text { Ewing } \\
\text { sarkom }\end{array}$ & 15 & $\mathrm{E}$ & $\begin{array}{l}\text { Yaşıyor( } \\
66 \text { ay) }\end{array}$ & Kitle & $\begin{array}{lr}\text { Skip } & \text { metastaz } \\
\text { nedeniyle } & \text { total } \\
\text { humerus protezi }\end{array}$ & 67 & 60 & 8 & 4 \\
\hline 4 & $\begin{array}{l}\text { Metastaz } \\
\text { (adeno } \\
\text { ca) }\end{array}$ & 71 & E & Ex(3 ay) & Kitle & Yok & 80 & 65 & 7 & 5 \\
\hline 5 & $\begin{array}{l}\text { Metastaz } \\
\text { (RCC) }\end{array}$ & 58 & $\mathrm{E}$ & $\begin{array}{l}\operatorname{Ex}(35 \\
\text { ay) }\end{array}$ & $\begin{array}{l}\text { Patolojik } \\
\text { Kırık }\end{array}$ & Yok & 76 & 45 & 9 & 6 \\
\hline 6 & $\begin{array}{l}\text { Metastaz } \\
\text { (Meme) }\end{array}$ & 65 & K & $\begin{array}{l}\text { Yaşıyor( } \\
38 \text { ay) }\end{array}$ & Kitle & Yara yeri enfeksiyonu & 93 & 70 & 7 & 4 \\
\hline 7 & $\begin{array}{l}\text { Metastaz } \\
\text { (Karsino } \\
\text { m) }\end{array}$ & 61 & K & $\operatorname{Ex}(9$ ay) & Kitle & Yok & 76 & 65 & 8 & 4 \\
\hline 8 & $\begin{array}{l}\text { Metastaz } \\
\text { (Akciğer }\end{array}$ & 71 & $\mathrm{E}$ & $\begin{array}{l}\operatorname{Ex}(12 \\
\text { ay) }\end{array}$ & $\begin{array}{l}\text { Patolojik } \\
\text { kırık }\end{array}$ & Yok & 67 & 45 & 9 & 5 \\
\hline 9 & $\begin{array}{l}\text { Yumuşak } \\
\text { doku(Fib } \\
\text { rosarkom }\end{array}$ & 24 & $\mathrm{E}$ & $\begin{array}{l}\text { Yaşıyor( } \\
21 \text { ay) }\end{array}$ & Kitle & $\begin{array}{ll}\text { Ulnada periprostatik } \\
\text { kırık }\end{array}$ & 80 & 75 & 8 & 5 \\
\hline 10 & $\begin{array}{l}\text { Dirsek } \\
\text { protezi } \\
\text { gevşeme }\end{array}$ & 75 & K & $\begin{array}{l}\text { Yaşıyor( } \\
6 \text { ay) }\end{array}$ & Ağr1 & Yok & 76 & 65 & 6 & 4 \\
\hline 11 & $\begin{array}{l}\text { Dirsek } \\
\text { protezi } \\
\text { gevşeme }\end{array}$ & 54 & $\mathrm{E}$ & $\begin{array}{l}\text { Yaşıyor( } \\
4 \text { ay) }\end{array}$ & Ağr1 & $\begin{array}{l}\text { Ulnada periprostatik } \\
\text { kırık }\end{array}$ & 67 & 60 & 6 & 4 \\
\hline 12 & $\begin{array}{l}\text { Dev } \\
\text { hücreli } \\
\text { tümör }\end{array}$ & 18 & $\mathrm{E}$ & $\begin{array}{l}\text { Yaşıyor( } \\
120 \text { ay) }\end{array}$ & Kitle & Yok & 93 & 80 & 6 & 4 \\
\hline
\end{tabular}

Adress for correspondence:Dr. Abdurrahman Yurtaslan Ankara Onkoloji Eğitim ve Araştırma Hastanesi 06580 Ankara/Türkiye 


\section{Tartışma}

Dirsek çevresi tümörleri yerleşim yeri olarak nadir olması nedeniyle geniş serilere ulaşmak zordur. Bu bölgenin anatomik olarak kompleks ve hayati damar sinir yapıları içermesinden dolayı operasyonları güçlük göstermektedir. Pek çok maliğn primer veya metastatik kemik tümörünün bu bölgede damar sinir tutulumu yapmas1 nedeniyle ilgili ekstremite de fonksiyonel kayıplar gözlenebilmektedir. Radyoterapi ve kemoterapi tedavileri gelişmeden önce tümörün lokal kontrolü sağlanması oldukça güç olmakta ve çoğunlukla bu tür vakalarda amputasyon yapılmak zorunda kalınmaktaydı. Günümüzde çok yönlü tedavi yaklaşımı bu hastaların çoğunda ekstremite koruyucu kemik rezeksiyonu ve endoprotez ile rekonstruksiyon yapılma imkanını vermektedir.

Geleneksel dirsek protezleri tümör çıkarılması sonucu oluşacak büyük kemik defeklerinin tedavisi için yeterli olamamaktadır. $\mathrm{Bu}$ boşlukların tedavisin de osteoartiküler allogreft, allogreft-prostetik kompozit custommade yada modüler megaprotez den artrodeze kadar çok çeşitli tedavi seçenekleri mevcuttur( 8,9$)$. Artrodez ile önemli derecede ağr1 şikayetini tedavi etmiş olsa da dirsek eklemi hareketsiz olmaktadır(10,11). Özellikle onkolojik hastalar radyoterapi ve kemoterapi almas1 nedeniyle zaten allogreftle yapilan tedavilerde kemik kaynamas1 operasyonlarda beklenen sonuç alınamamaktadır. Enfeksiyon ve insitabilite allogreft ile yapilan rekonstrüksiyonlar da en s1k görülen komplikasyonlardır. Günümüz şartlarında artrodezden bir tedavi seçeneği olarak kaçınılmalıdır. Dirsek eklem protezi ile rekonstrüksiyon kozmetik ve duygusal olarak artrodezden her zaman hasta tarafindan daha çok kabul edilebilir olmaktadır.

Lokal nüks oranları özellikle tümör grade ve histolojisi ile değişkenlik göstermekle beraber bu oran osteosarkom da \%5 iken yumuşak doku sarkomların da \% 30 kadar çıkmaktadır. En yüksek nüks oranı metastazlara bağlı olarak gerçekleşmektedir(\%20-50)( 12). 1987 de Ross(13) ve arkadaşları ilk kez 26 hasta ile tümör ve kronik kaynamamaya bağlı custom made dirsek protezi yaptıkları seriyi yayınlamışlardır. Bu çalışmada ortalama dirsek ekstansiyonu 35 derece, fleksiyonu ortalama 117 derece olurken 3 hastada derin enfeksiyona bağlı protez, gevşeme nedeniyle çıkarılmıştır. 3 hastada sinir palsi gelişmiştir. 1999 da Sperling(14) ve arkadaşları ilk kez semiconstrained Coonrad-Morrey total dirsek protezi ni(Zimmer Corporation, Warsaw) distal humerus tutulumlu kemik tümörlerinin tedavisinde kullanmıştır. 13 hasta(7 primer, 6 metastatik) opere edilmiştir. Primer tümörlü hastalarda metastatik hastalara göre fonkiyonel sonuçların daha iyi olduğunu belirtmiştir. Aseptik gevşeme ve enfeksiyon bildirmemișlerdir.

2003 de Weber ve arkadaşları(15) segmental total dirsek protezini(Stryker Howmedica, Biomed) kullanmışlardır. 23 hasta üzerinde yaptıkları çalışmada 6 hastada(\%26) lokal nüks saptamışlardır. 4 hastada sinir palsi gelişmiştir.

Dirsek eklemi protez cerrahisin de enfeksiyon ve cilt nekrozu diğer önemli bir komplikasyonlardır. Cerrahi operasyon süresi ve protez çevresinin yumuşak doku ile yeterli derecede örtülmesinin bu komplikasyonların önlenmesinde önemli olduğunu düşünmekteyiz. Bizim bir vakamızda yüzeyel yara yeri enfeksiyonu görüldü. Medikal tedavi ile düzeldi.

Uzatılmış lateral yaklaşımın primer ve metastatik dirsek eklemi tümörlerinde, modüler distal semiconstrained endoprotez ile ekstremite koruyucu cerrahinin; ağrının azaltılması, fonksiyonel bir dirsek eklemine sahip olunmasında, düşük komplikasyon oranıyla posteriyor veya anteriyor yaklaşım kadar etkili olduğunu düşünmekteyiz.

Ekstremite koruyucu cerrahide amaç hastalığın lokal kontrolünü sağlayarak fonksiyonel bir dirsek eklemi elde etmektir. Özellikle humerus distalinde dirsek eklemine uzanan kemikte yıkım yapan, küretaj ve çimentolama gibi kemik koruyucu operasyon yapılamayan hastalarda bir seçenek olmaktadır. Kemik metastazlarına bağlı rekonstrüksiyon yapılan hastalarda beraberinde akciğer metastazı varlığı olması sonuçları ve hayatta kalma beklentilerini etkilemektedir. Ama bu hastalarda yapilacak bu cerrahi tedaviye ilaven akciğer metastazların temizlenmesi hayatta kalmaya önemli katkı sağlamaktadır. Hastalarda lokal nüks sıklığı primer veya metastatik hastalığın biyolojik davranışı ve yapılan cerrahi rezeksiyonun kalitesine bağlıdır. $\mathrm{Bu}$ operasyonlara bağlı gelişen en sık 
komplikasyon sinir zedelenmeleridir. Bu oran \%17-31 arasında değişmektedir $(16,17,18)$. Bizim 1 hastamızda operasyon sirasinda traksiyona bağlı radial sinir zedelenmesi gelişmiş oda 6 ay içinde spontan düzelmiştir. Hiç bir hastamızda enfeksiyona bağlı protez çıkarılmasını gerektirecek bir durum olmamıştır. Özellikle operasyonlardan sonra rotasyonel yada serbest doku flebi kullanılması enfeksiyon oranını düşürmektedir.

Hastalarımızda ortalama MSTS skoru 77(67-93) ile iyi sonuç olarak gerçekleşmiştir. En kötü sonuç elde ettiğimiz hastamız Ewing sarkom nedeniyle ameliyat ettiğimiz ve sonrasinda humerus proksimalin de skip metastaz gelişmesi nedeniyle total humerusa dönüş yaptığımız genç hastamızdı. Literatürde metastatik olgular da fonksiyonel sonucun daha kötü olduğu bildirilse de bizim sonuçlarımız her iki gurup içinde aynıdı. Dean ve arkadaşları(19) allogreft ile rekonstruksiyon yaptıkları 23 hasta ile ilgili çalışmada \% 70 komplikasyon bildirmişler ve bu tür büyük kemik defekti oluşan vakalar da allogreft kullanımını önermemişlerdir. Nitekim bizim vakalarımızda da olduğu gibi dirsek protezi ile başarı oranları daha yüksek olduğu kadar revizyon oranları da son derece düşüktür. Hastaların çoğunluğun da fonksiyonel ağrısız bir dirsek eklemi, ön kol ve el bileği eklemi sağlamak mümkündür.

Sonuç olarak dirsek eklemine modüler endoprotez uygulanan hastalarda yüksek oranda ağrısız bir dirsek, ön kol ve el bileği eklemi elde edilmekte, hasta ameliyattan sonra kısa süre içinde ilgili ekstremitesini kullanmaya başlamaktadır. Dahası yeterli cerrahi sınır elde edilmesini sağlayan agresif bir rezeksiyon; bu bölgeyi tutan primer lokal agresif tümörlerde potansiyel bir kür sağlayabilmektedir, ancak metastatik tümörlerde yeterli bir fonksiyonel sonuç sağlamasına karşın total yaşam beklentisine çok katkı sağlamamaktadır.

\section{Referanslar:}

1. Pritchard DJ, Dahlin DC: Neoplasms of the Elbow. In Morrey BF (ed). The Elbow and Its Disorders Philadelphia,WB Saunders 1985;713-35

2. Hanna SA, David LA, Aston WJ, et al. Endoprosthetic replacement of the distal humerus

19. Dean GS, Holliger EH IV, Urbaniak JR: Elbow allograft for reconstruction of the elbow with massive bone loss: Long term results. Clin Orthop. 1997; 341:12-22 following resection of bone tumors. J Bone Joint Surg Br. 2007;89:1498-503

3. Sperling JW, Pritchard DJ, Morrey BF. Total elbow arthroplasty after resection of tumors at the elbow. Clin Orthop Relat Res. 1999;367:256-61

4. Morrey BF, Adams RA. Semiconstrained arthroplasty for the treatment of rheumatoid arthritis of the elbow. J Bone Joint Surg Am. 1992;74:979-90.

5. Enneking WF, Dunham W, Gebhardt MC, Malawar M, Pritchard DJ: A system for the functional evaluation of reconstructive procedures after surgical treatment of tumors of the musculoskeletal system. Clin Orthop 286:241-246, 1993.

6. Morrey BF, Adams RA. Semiconstrained arthroplasty for the treatment of rheumatoid arthritis of the elbow. J Bone Joint Surg Am. 1992;74:479-90

7. Wewers ME, Lowe NK. A critical review of visual analogue scales in the measurement of clinical phenomena. Research in Nursing \& Health1990; 13:227-36

8. Mansat P, Adams RA, Morrey BF. Allograftprosthesis composite for revision of catastrophic failure of total elbow arthroplasty. J Bone Joint Surg Am. 2004;86:724-35

9. Morrey ME, Sanchez-Sotelo J, Abdel MP, Morrey BF. Allograft-prosthetic composite reconstruction for massive bone loss including catastrophic failure in total elbow arthroplasty. J Bone Joint Surg Am. 2013;95:1117-24

10. Koller H, Kolb K, Assuncao A, Kolb W, Holz U. The fate of elbow arthrodesis: indications, techniques, and outcome in fourteen patients. J Shoulder Elbow Surg. 2008;17:293-306.

11. Moghaddam-Alvandi A, Dremel E, Guven F et al. Arthrodesis of the elbow joint. Indications, surgical technique and clinical results. Unfallchirurg 2010;113:300-7

12. Weber KL, Lin PP, Yasko AW. Complex segmental elbow reconstruction after tumor resection. Clin Orthop Relat Res. 2003;415:31-44.

13. Ross AC, Sneath RS, Scales JT. Endoprosthetic Replacement of the humerus and elbow joint. J Bone Joint Surg Br. 1987;69:652-5

14. Sperling JW, Pritchard DJ, Morrey BF. Total elbow arthroplasty after resection of tumors at the elbow. Clin Orthop Relat Res. 1999 ;367:256-61

15. Weber KL, Lin PP, Yasko AW. Complex segmental elbow reconstruction after tumor resection. Clin Orthop Relat Res. 2003;415:31-44

16. Dean GS, Holliger EH IV, Urbaniak JR: Elbow allograft for reconstruction of the elbow with massive bone loss: Long term results. Clin Orthop 1997;341:12-22

17. Hildebrand KA, Patterson SD, Regan WD, MacDermid JC, King GJ: Functional outcome of semiconstrained total elbow arthroplasty. J Bone Joint Surg. 2000; 82:1379-86

18. Ross AC, Sneath RS, Scales JT: Endoprosthetic replacement of the humerus and elbow joint. J Bone Joint Surg. 1987; 69:652-55 